\section{EMT}

EQUIPMENT AND MATERIALS TECHNOLOGY

\section{SD? $8>10,03$ \\ OSTI}

Keywords: Nondestructive Examination Ultrasonic Inspection General Purpose Heat Source

Retention:

Permanent

\title{
ULTRASONIC TECHNIQUE FOR INSPECTION OF GPHS CAPSULE GIRTH WELD INTEGRITY (U)
}

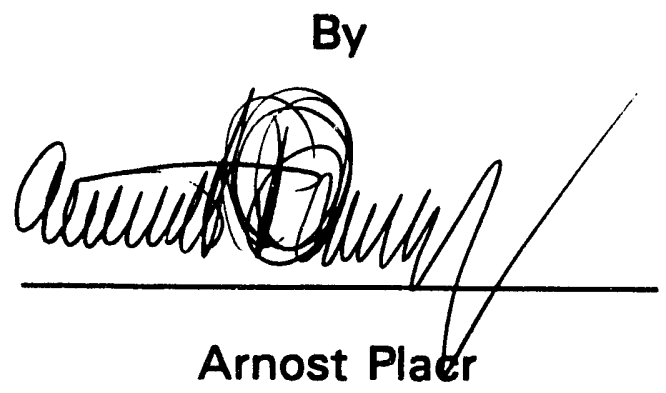

issued: May, 1993

UNCLASSIFIED

DOES NOT CONTAIN UNCLASSIFIED CONTROLLED NUCLEAR INFORMATION

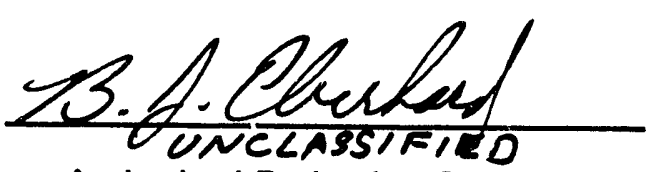

Authorized Derivative Classifier

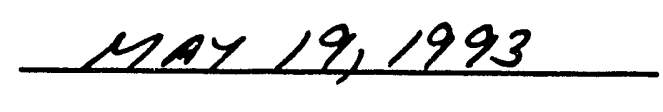

Date

SRTC savannah river technology Center, aIKen, sc 29808

Westinghouse Savannah River Company

Prepared for the U.S. Department of Energy under Contract DE-AC09-88SR18035 
DOCUMENT: WSRC-TR-93-299

TITLE:

ULTRASONIC TECHNIQUE FOR INSPECTION OF GPHS CAPSULE GIRTH WELD INTEGRITY (U)

APPROVALS

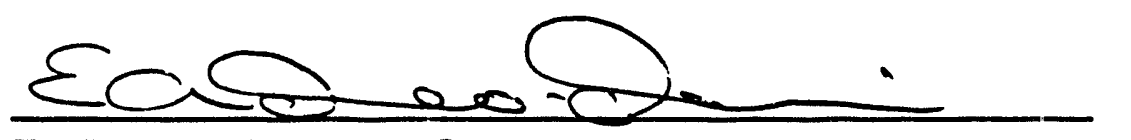

Ed Franco-Ferreira, Customer Review SRTC/EMT/SPS/Weld Engineering

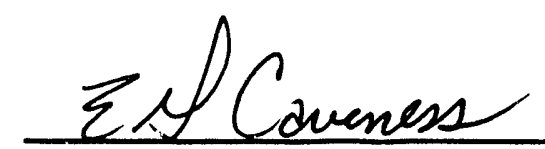

E.G. Caveness, Manager SRTC/EMT/Special Processes Section

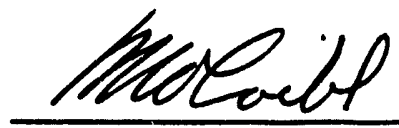

M.W. Loibl, Manager

SRTC/EMT/SPS/NDE Technology Application Group

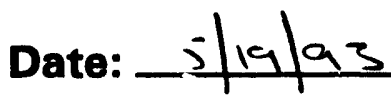

Date: $5 / 20 / 93$

Date: $5 / 20 / 83$ 


\section{TABLE OF CONTENTS}

Page \#

SUMMARY

HISTORY

REFERENCE STANDARD

DEVELOPMENT OF INSPECTION TECHNIQUE

$2-4$

FINAL INSPECTION TECHNIQUE

FIGURES

5

CONCLUSIONS

ACKNOWLEDGEMENTS

REFERENCES

PICTURES AND IMAGES

$6-18$ 


\section{SUMMARY}

An innovative nondestructive examination (NDE) technique for the inspection of integrity of General Purpose Heat Source (GPHS) capsule girth welds (Figure 1) was developed employing a Lamb (plate) wave as the mode of the sound propagation. Reliability of the Lamb wave technique was tested on GPHS capsules using plutonium pallet simulators. All ten capsules, which were previously rejected, passed ultrasonic (UT) inspection using the Lamb wave technique.

\section{HISTORY}

In the early '80s, Savannah River Plant (SRP) developed an ultrasonic technique for inspection of GPHS capsule girth welds. An immersion method was utilized by placing the part in a small tank filled with circulating water. The part was held in the vertical position by a clamping device attached to a rotary table. A 1.0 inch focused distance, 0.25 inch diameter transducer, oscillating at a frequency of $5.0 \mathrm{MHz}$, at fixed, $31^{\circ}$ $\left(31.15^{\circ}\right.$ ) angle of incidence (Figure 3 and 4 ) scanned the weld. Based on correlation between thickness of the material and wavelength $\langle 1\rangle$, the mode of sound propagation was a surface (Rayleigh) wave $<2>$.

$$
\begin{aligned}
& \langle 1\rangle \\
& <2> \\
& \lambda=\mathrm{c} / \mathrm{f}=0.0225^{n} \\
& \lambda<\mathrm{T}
\end{aligned}
$$

The first series of GPHS capsules for the Galileo project was successfully manufactured and tested. Another need for GPHS capsules, at this time for the Cassini project, arrived. The DOE accepted a proposal for replacement of the old SRP equipment by a modern technology system. Identical systems were installed in Los Alamos NL, Oak Ridge Y-12 Plant and Westinghouse Savannah River Site. The original SRP concept $\left(31^{\circ}\right.$ technique) was adopted. The $5.0 \mathrm{MHz}$ transducer was replaced by a $3.5 \mathrm{MHz}, 0.5^{\text {" }}$ diameter transducer, and the strip chart recorder by a color C-scan image.

The new inspection system, technique and procedure were examined for their performance in October 1992 in Los Alamos NL with a disappointing result. The product rejection rate exceeded 90 percent. The reason for reject ion were indications exceeding the acceptance threshold of 0.0052 inch equivalent depth. Rejected capsules were then opened and visually analyzed. The analysis revealed, that all capsules were rejected due to reflections from geometric irregularities (Figure $2 a$ and 
2b) on inner and/or outer surface of welds, or due to strong indications caused by the heat shield fusion (Figure 2e). None of these capsules had a crack-like-flaw (Figure 2f), exceeding acceptance level.

These results led to an urgent development of an alternate technique with a detection capability to accurately characterize crack-like-flaws, while suppressing sensitivity to geometric reflectors.

\section{REFERENCE STANDARD}

A reference standard, as presented by Figure 7, having EDM notches of different dimensions, orientation and different locations, was used during the development period to maintain identical response from simulated flaws using various scanning techniques. Table 1 below shows dimensional and other parameters of the reference standard.

\begin{tabular}{|c|c|c|c|c|c|c|}
\hline $\begin{array}{c}\text { Notch } \\
\text { No. }\end{array}$ & $\begin{array}{c}\text { Depth } \\
\pm 0.0005\end{array}$ & Orientation & $\begin{array}{c}\text { Distance from } \\
\text { Centerline }\end{array}$ & $\begin{array}{c}\text { Width } \\
\pm 0.001\end{array}$ & $\begin{array}{c}\text { Length } \\
\pm 0.002\end{array}$ & $\begin{array}{c}\text { Angle } \\
\pm 2^{\circ}\end{array}$ \\
\hline 1 & 0.002 & Vertical & 0.150 & 0.004 & 0.050 & $0^{\circ}$ \\
\hline 2 & 0.003 & Vertical & 0.150 & 0.004 & 0.050 & $30^{\circ}$ \\
\hline 3 & 0.006 & Vertical & 0.150 & 0.004 & 0.050 & $60^{\circ}$ \\
\hline 4 & 0.009 & Vertical & 0.150 & 0.004 & 0.050 & $90^{\circ}$ \\
\hline 5 & 0.006 & Vertical & 0.030 & 0.004 & 0.050 & $120^{\circ}$ \\
\hline 6 & 0.003 & Horizontal & 0.030 & 0.004 & 0.050 & $150^{\circ}$ \\
\hline 7 & 0.006 & Horizontal & 0.030 & 0.004 & 0.050 & $180^{\circ}$ \\
\hline 8 & 0.003 & Horizontal & 0.150 & 0.010 & 0.050 & $210^{\circ}$ \\
\hline 9 & 0.002 & Horizontal & 0.150 & 0.004 & 0.050 & $240^{\circ}$ \\
\hline 10 & 0.003 & Horizontal & 0.150 & 0.004 & 0.050 & $270^{\circ}$ \\
\hline 11 & 0.006 & Horizontal & 0.150 & 0.004 & 0.050 & $300^{\circ}$ \\
\hline 12 & 0.009 & Horizontal & 0.150 & 0.004 & 0.050 & $330^{\circ}$ \\
\hline
\end{tabular}

Table 1

\section{DEVELOPMENT OF INSPECTION TECHNIQUE}

The first attempt was focused on verification of known techniques (including the $31^{\circ}$ surface wave) as illustrated on Figure 3. Table 2 summarizes incidence/refracted angles involved in this investigation and Table 3 provides some physical and acoustical properties. 


\begin{tabular}{|c|c|c|}
\hline $\begin{array}{c}\Delta \alpha \\
\text { Incidence angle }\end{array}$ & $\begin{array}{c}\Delta \beta \\
\text { Refracted angle }\end{array}$ & $\begin{array}{c}\text { Mode } \\
\text { of wave propagation }\end{array}$ \\
\hline $11.38^{\circ}$ & $45^{\circ}$ & Longitudinal (Compressional) \\
\hline $19.60^{\circ}$ & $45^{\circ}$ & Transverse (Shear) \\
\hline $13.90^{\circ}$ & $60^{\circ}$ & Longitudinal (Compressional) \\
\hline $24.30^{\circ}$ & $60^{\circ}$ & Transverse (Shear) \\
\hline $31.15^{\circ}$ & $90^{\circ}$ & Rayleigh (Surface) wave \\
\hline
\end{tabular}

Table 2

\begin{tabular}{|l|c|c|}
\hline Iridium longitudinal wave velocity & $0.209 \mathrm{in} / \mu \mathrm{s}$ & $5.31 \mathrm{~mm} / \mu \mathrm{s}$ \\
\hline Iridium transverse wave velocity & $0.129 \mathrm{in} / \mu \mathrm{s}$ & $3.12 \mathrm{~mm} / \mu \mathrm{s}$ \\
\hline Iridium surface wave velocity & $0.113 \mathrm{in} / \mu \mathrm{s}$ & $2.86 \mathrm{~mm} / \mu \mathrm{s}$ \\
\hline Water longitudinal wave velocity & $0.058 \mathrm{in} / \mu \mathrm{s}$ & $1.48 \mathrm{~mm} / \mu \mathrm{s}$ \\
\hline GPHS capsule nominal wall-thickness & $0.025 \mathrm{in}$ & $0.649 \mathrm{~mm}$ \\
\hline
\end{tabular}

Table 3

None of the techniques listed in Table 2 and Figure 3 were suitable for this type of inspection. The following is a list of some disadvantages:

- Entry surface echo is unstable in height and position.

- Inadequate metal path/time separation - Figuie 3 and 6.

- Background/noise is strong/high - Figure 11.

- Setup of a gate is difficult.

- Oversensitive to geometric reflectors - Figure $2 \mathrm{a}$ and $\mathbf{2 b}$.

- High rate of rejection.

The only viable remaining alternatives were angles of incidence higher than $31.15^{\circ}$. These angles could generate Lamb waves provided ine correlation between the material thickness, frequency and the sound beam entry point la matter of part configuration) are in full compliance with physical principles. A $39^{\circ}$ angle from horizontal $\left(35^{\circ}\right.$ angle of incidence) was the first useful, Lamb wave operational mode. Using the system's turn table and " $Z$ " axis, it was experimentally determined that the optimum entry point (for \#11 notch) was just above the beginning of the 0.205 inch nominal radius, on the vertical portion of the part, as illustrated on Figure 5 . This technique solved most of the difficulties associated with the $31^{\circ}$ technique:

- Entry surface echo is stable in height and position. 
- Time separation increased significantly - Figure 6.

- Background/noise decreased - Figure 12.

- Setup of the gate causes no more problem.

- Less sensitive to geometric reflectors.

One problem remained: a high percentage of rejected parts. Approximately $50 \%$ of the examined parts did not passed inspection due to strong indications from geometric reflectors.

\section{FINAL INSPECTION TECHNIQUE}

The techniques described above, use a turn table as a scanning axis and " $\mathrm{Z \text {"motion }}$ (vertical) for indexing. The intent was to scan the part with the transducer pointing directly down on the top of the capsule, parallel to the capsule main axis. Figure 8 describes the setıp. The angle of incidence is naturally, unmistakably and automatically changing from $90^{\circ}$ to $0^{\circ}$ by the radius of the part during scanning. The optimum entry point location, at $19.52^{\circ}$ angle to the vertical, is related exclusively to the maximum response from the 0.006 inch deep notch (notch \#11, Figure 7). There are two different scanning techniques, Option $A$ and Option B, with identical results. Option $A$ uses the turn table as a scanning axis, and, in contrast with previous techniques, $X$ or $Y$ axis for indexing. Option B consists of a "zig-zag" $X-Y$ pattern, while the part is stationary (static). Figure 13 shows a C-scan image of the reference standard, created by Option A, X-Y scan. Figure 14 represents same part, scanned by choosing eption $B$. The left portion of the image clearly shows the sequence of notch \#12,11,10,9 and 8,0.150 inch above the weld, and \#6 and 3 , 0.030 inch above weld centerline (counterclockwise) and their plan view layout, exactly as drawn on Figure 7. The top right window presents a zoomed out image of the \#11 notch, and the \#12 notch in the bottom right window.

This Lamb wave technique was found to be the most favorable one. Advantages of the $20^{\circ}$ top scan technique are:

- The simplest technique with respect to system setup, human or system error, operator skills, etc.

- Excellent repeatability.

- Entry surface echo is stable.

- Weld centerline can be accurately spotted.

- Time separation more than adequate - Figure 6.

- Background/noise dropped almost to zero - Figure 13, 14 and 15.

- Setup of the gate is simple, and the gate itself can be very short.

- The least sensitive technique to geometric reflectors.

- The lowest rate of rejections. 


\section{FIQURES}

Figure 9 is a graphical expression of UT responses from notches \#6 to \#12 in the reference standard on Figure 7, utilizing various techniques.

Figure 10 is a simplified Lamb wave mode and velocity evaluation diagram (Ref. 1 ). The GPHS capsule nominal wall-thickness is $0.649 \mathrm{~mm}$. A peak frequency of the transducer used for this development was $3.12 \mathrm{MHz}$.

Figure 15 provides an example of a production part (\#36) with acceptable result. The indication in the middle represents the weld overlap (welding process start/end) and the narrow indication to the right, a crack-like-flaw.

NOTE: Although, the $20^{\circ}$ top scan technique is insensitive to reflectors caused by geometric irregularities, there is no guarantee that defects similar to $\varepsilon$ (misalignment) and $d$ (lack of fusion) on Figure 2, or other sharp transitions, will be ignored, not generating strong indications that could result in the part rejection.

\section{CONCLUSIONS}

The $20^{\circ}$ top scan inspection technique was approved for the Cassini production by the GPHS Welding/UT Working Group on GPHS Technical Meeting in Pittsburgh, PA, April 15, 1993, and further verified by Oak Ridge Y-12 Plant, Development Division.

\section{ACKNOWLEDGEMENTS}

This development was accomplished by the SRTC Equipment $\&$ Materials Technology Department, Special Processes Section, NDE Technology Application Group. The following individuals participated in the effort to complete this task: Jim Wilderman (photography) and Boyd Howard (PT test, replicas, analysis).

\section{REFERENCES}

1. Josef Krautkrămer/Herbert Krautkrămer, "Ultrasonic Testing of Materials", 1983, Third Edition. 


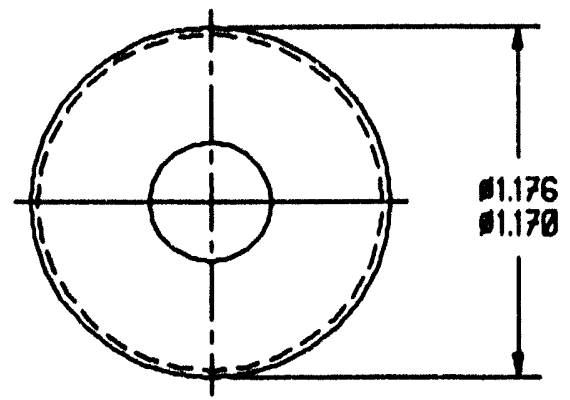

TOP VIEW

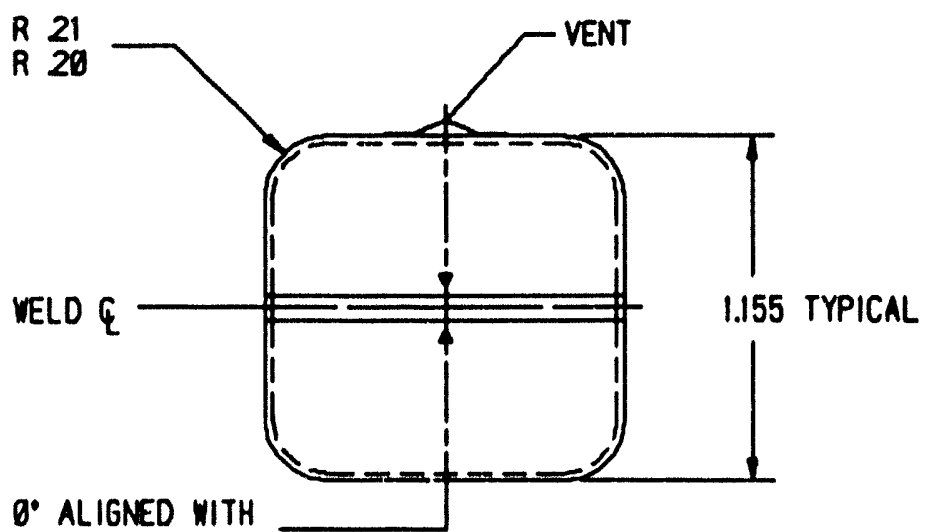
ETCHED V-MARKS

\section{ERONT VIEW}

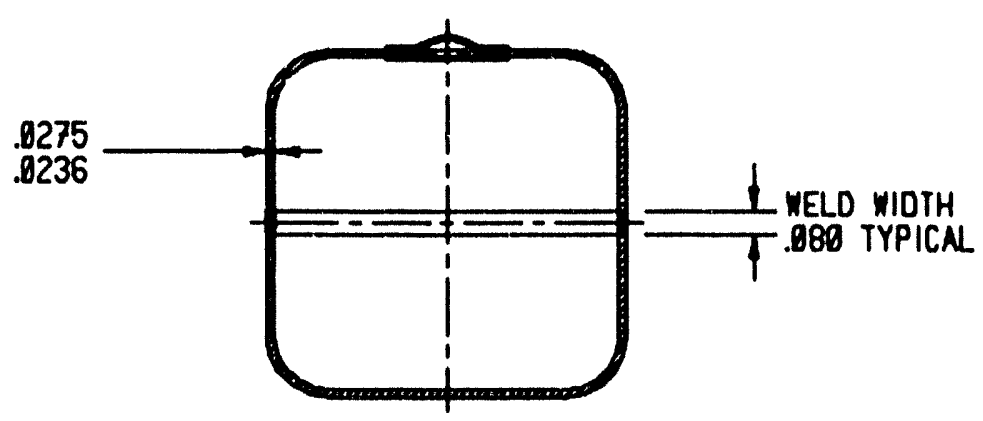

CROSS-SECTIONAL VIEW

Figure 1. GPHS Capsule Assembly 


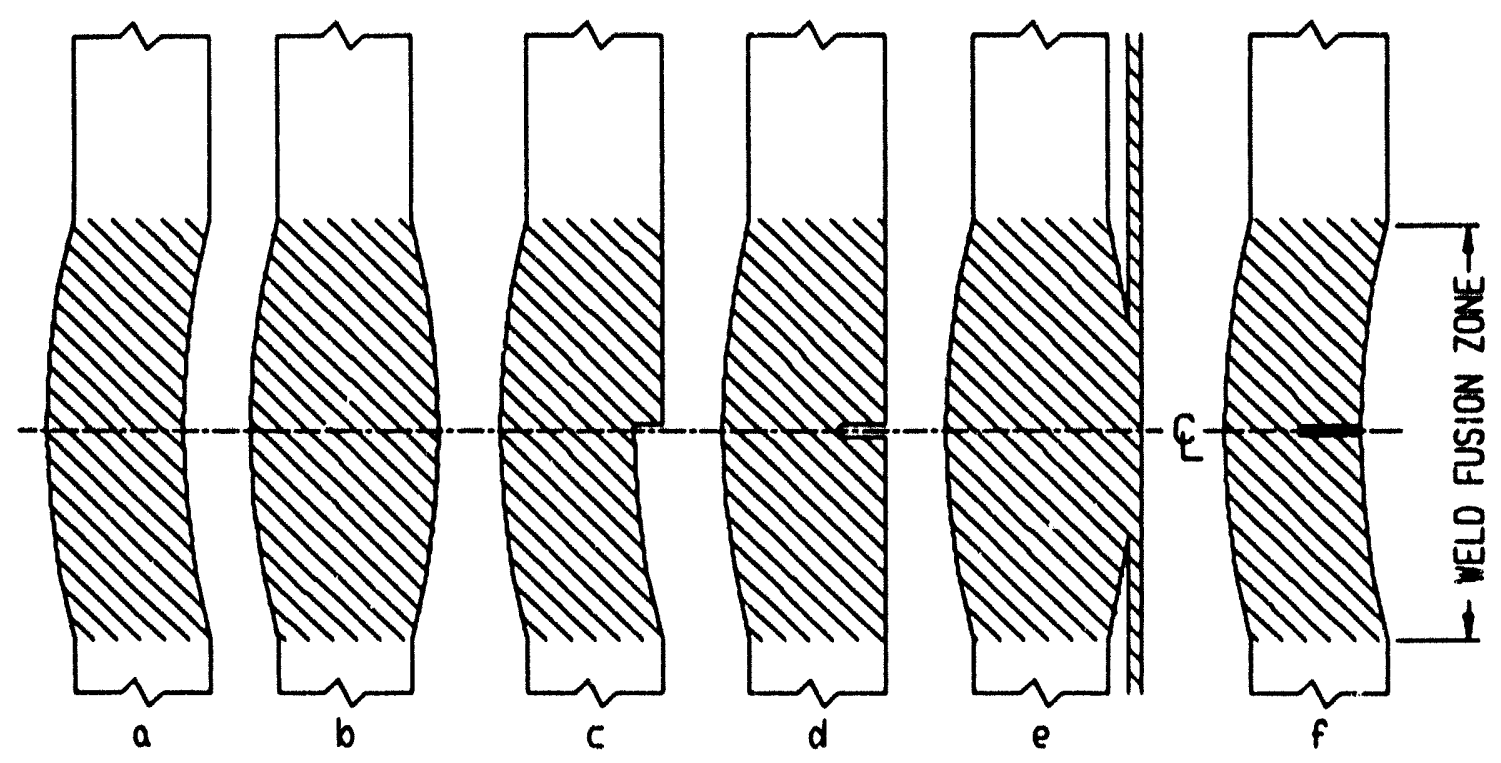

Figure 2. Possible Weld Imperfections and Flaws

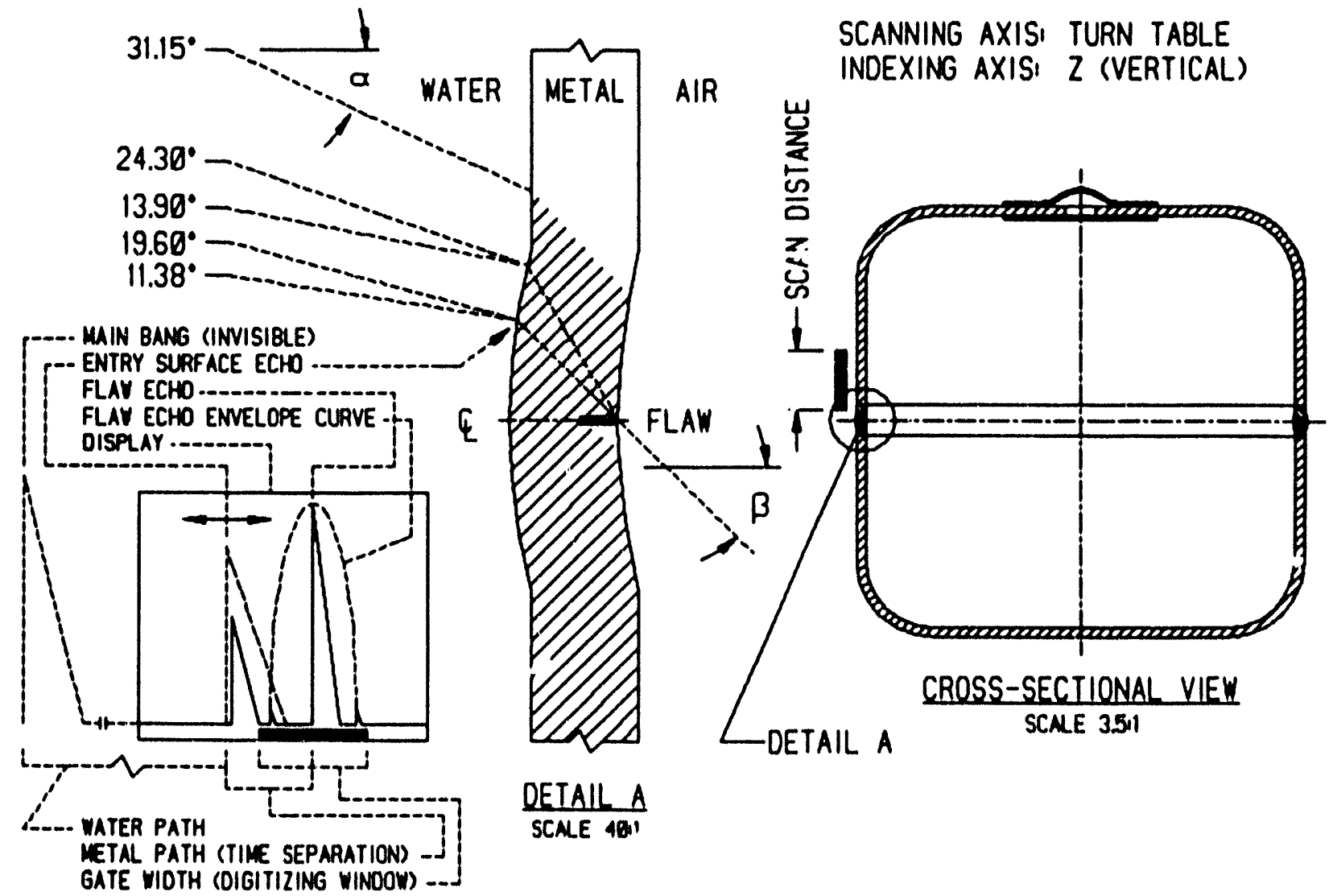

Figure 3. Scanning Techniques 
Arnost Placr

May, 1993
WSRC-TR-93-299

Page 8
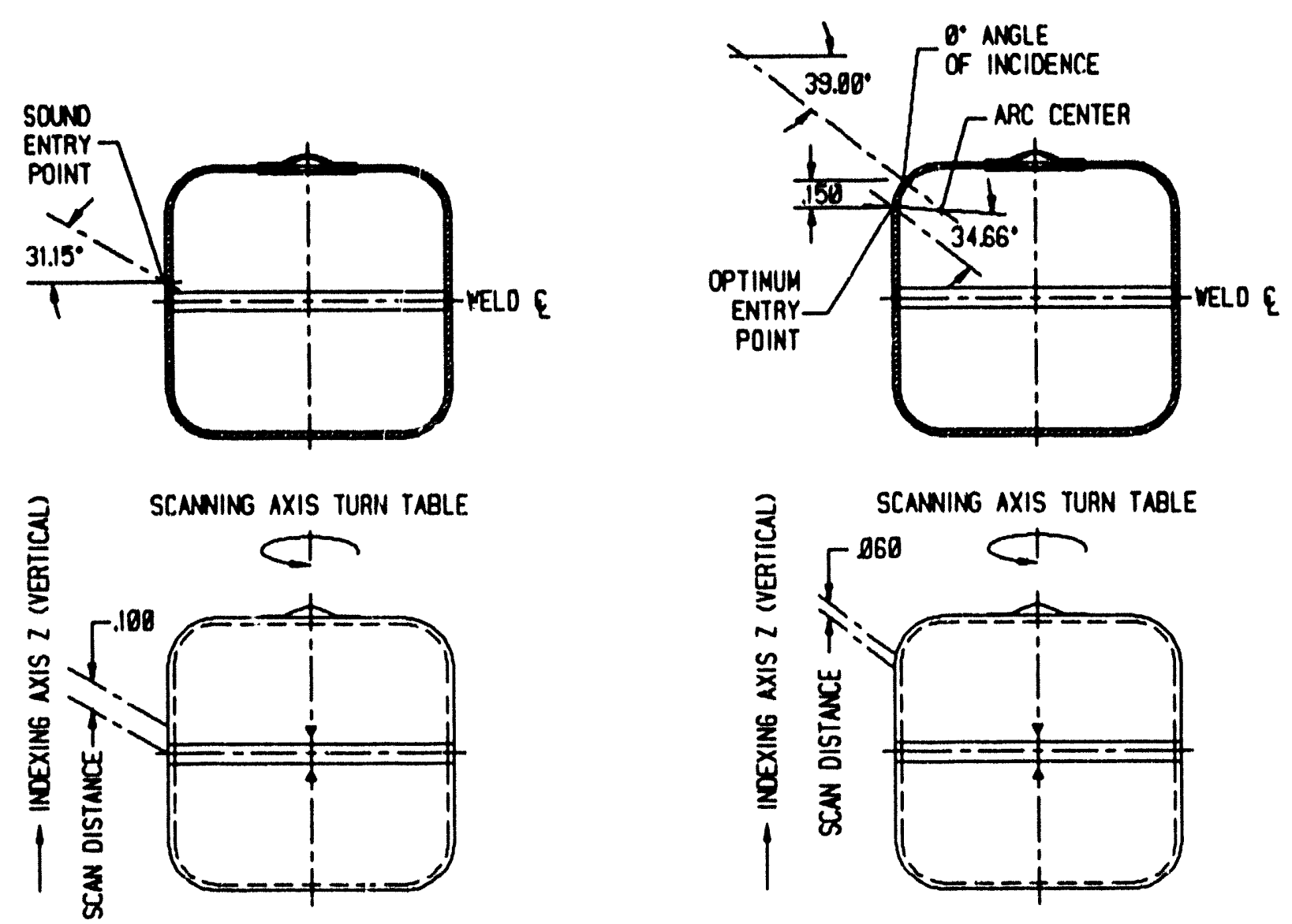

Figure 4. $31^{\circ}$ Technique-Surface Wave

Figure 5. $39^{\circ}$ Technique-Lamb Wave 
Arnost Placr

May, 1993
WSRC-TR-93.299

Page 9

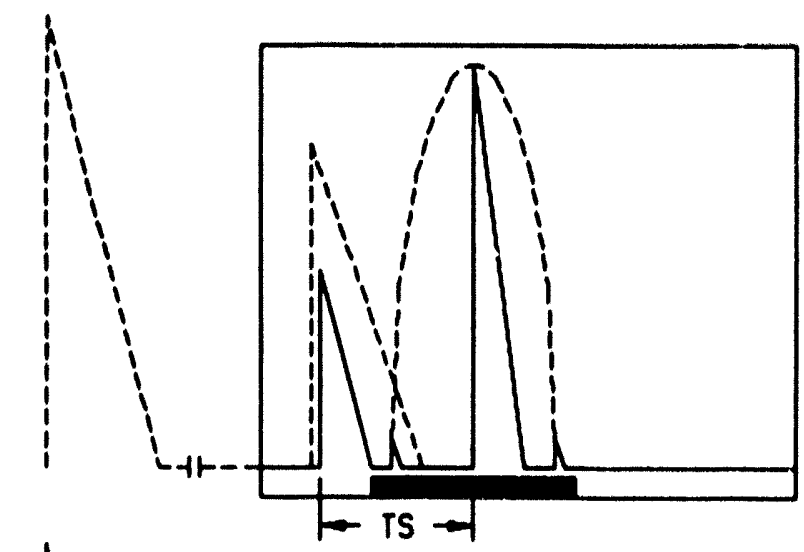

TS = TIME SEPARATION
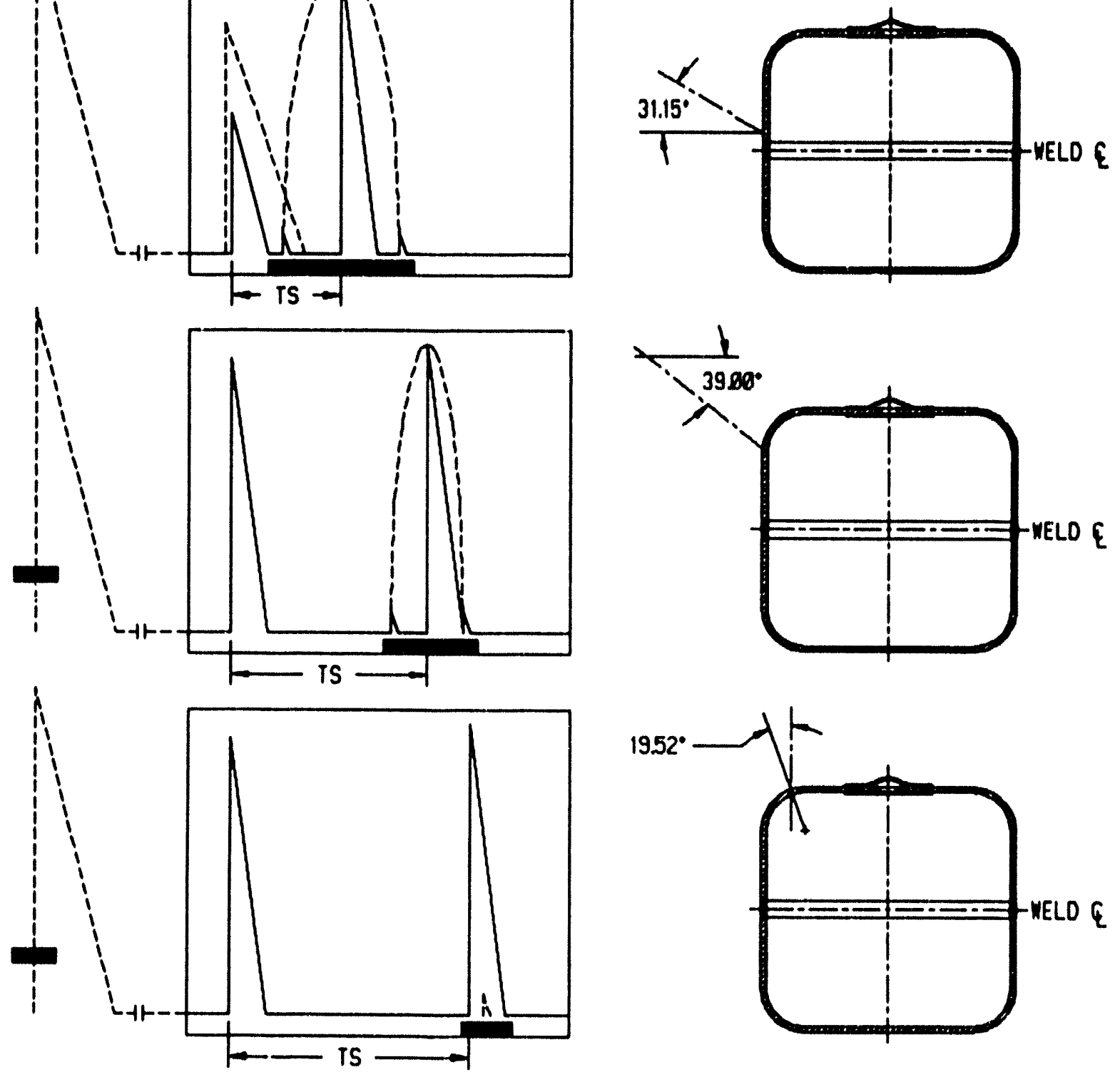

Figure 6. UT Instrument Screen Presentation 

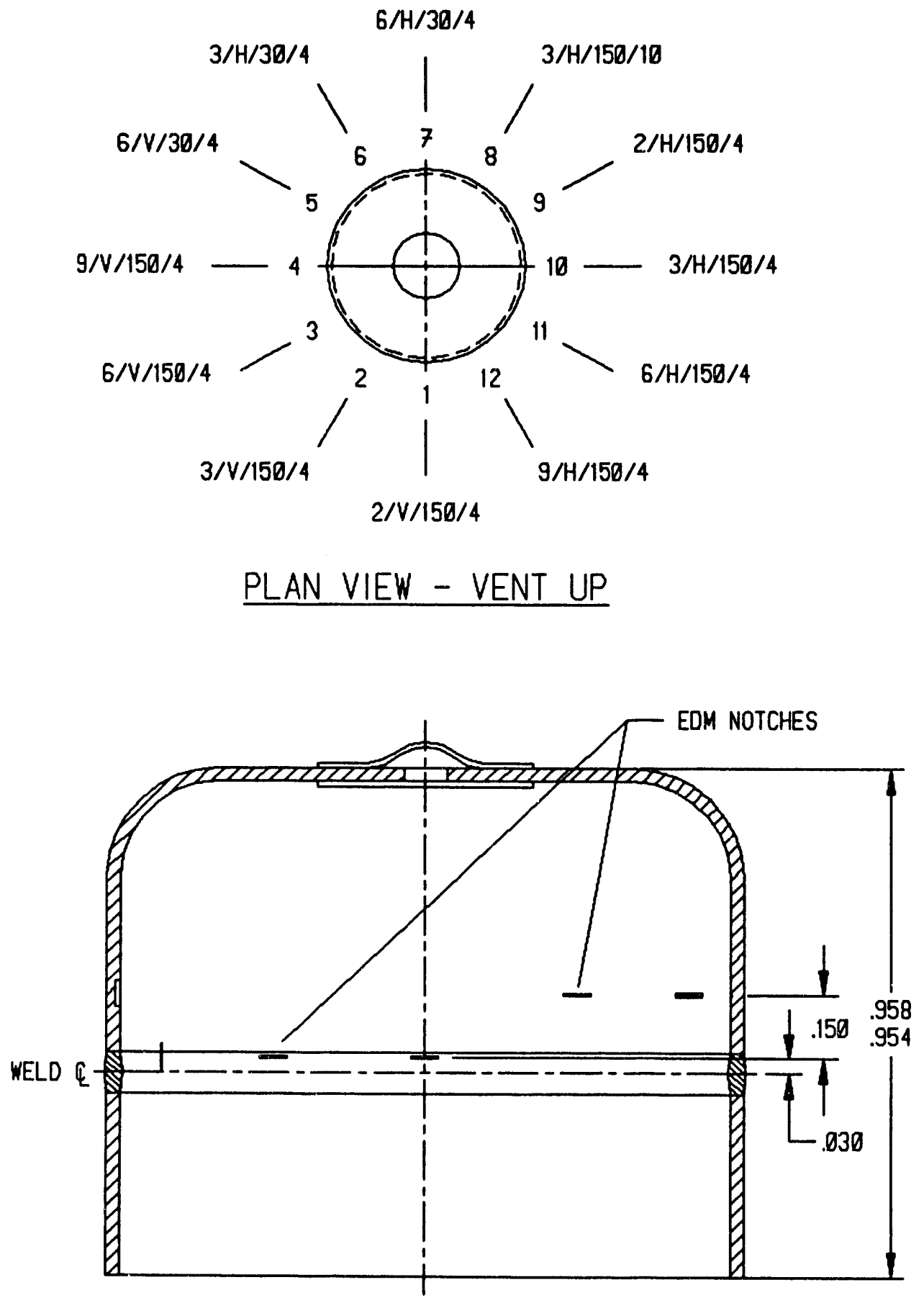

ENLARGED CROSS-SECTIONAL VIEW

Figure 7. Reference Standard Assembly 


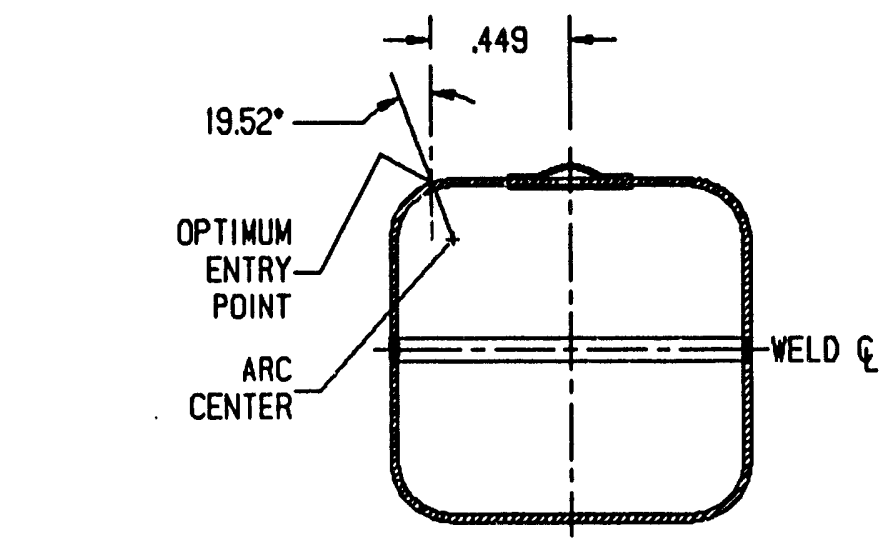

SCANNING AXIS TURN TABLE

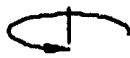

INDEXING AXIS $X$ or $Y$ (HORIZONTAL)
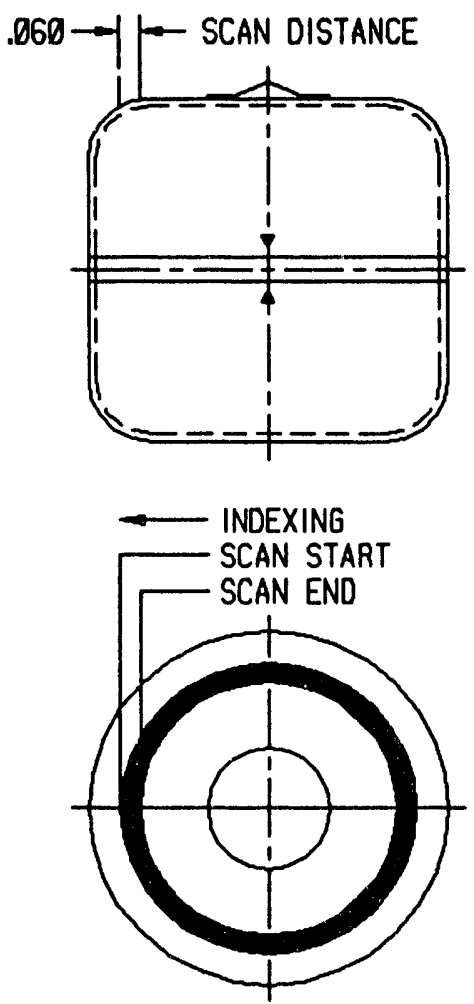

TOP VIEW

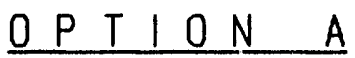

SCANNING AXIS $X$ (HORIZONTAL) INDEXING AXIS Y (HORIZONTAL)

SCAN DISTANCE = INDEX DISTANCE

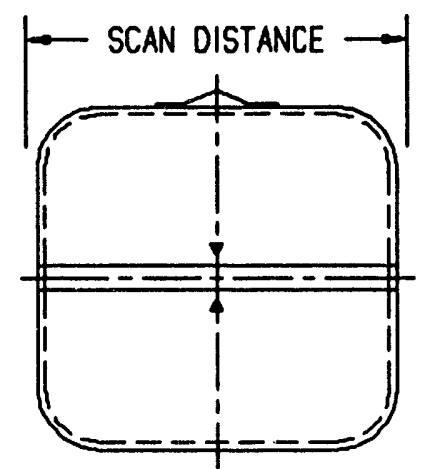

ZIG-ZAG PATTERN

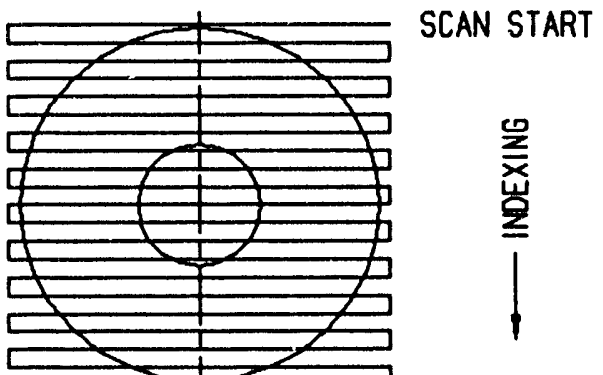

SCAN END

$$
\text { TOP VIEW }
$$

OP T $10 \mathrm{~N} B$

Figure 8. $20^{\circ}$ Top Scan Final Technique-Lamb Wave 


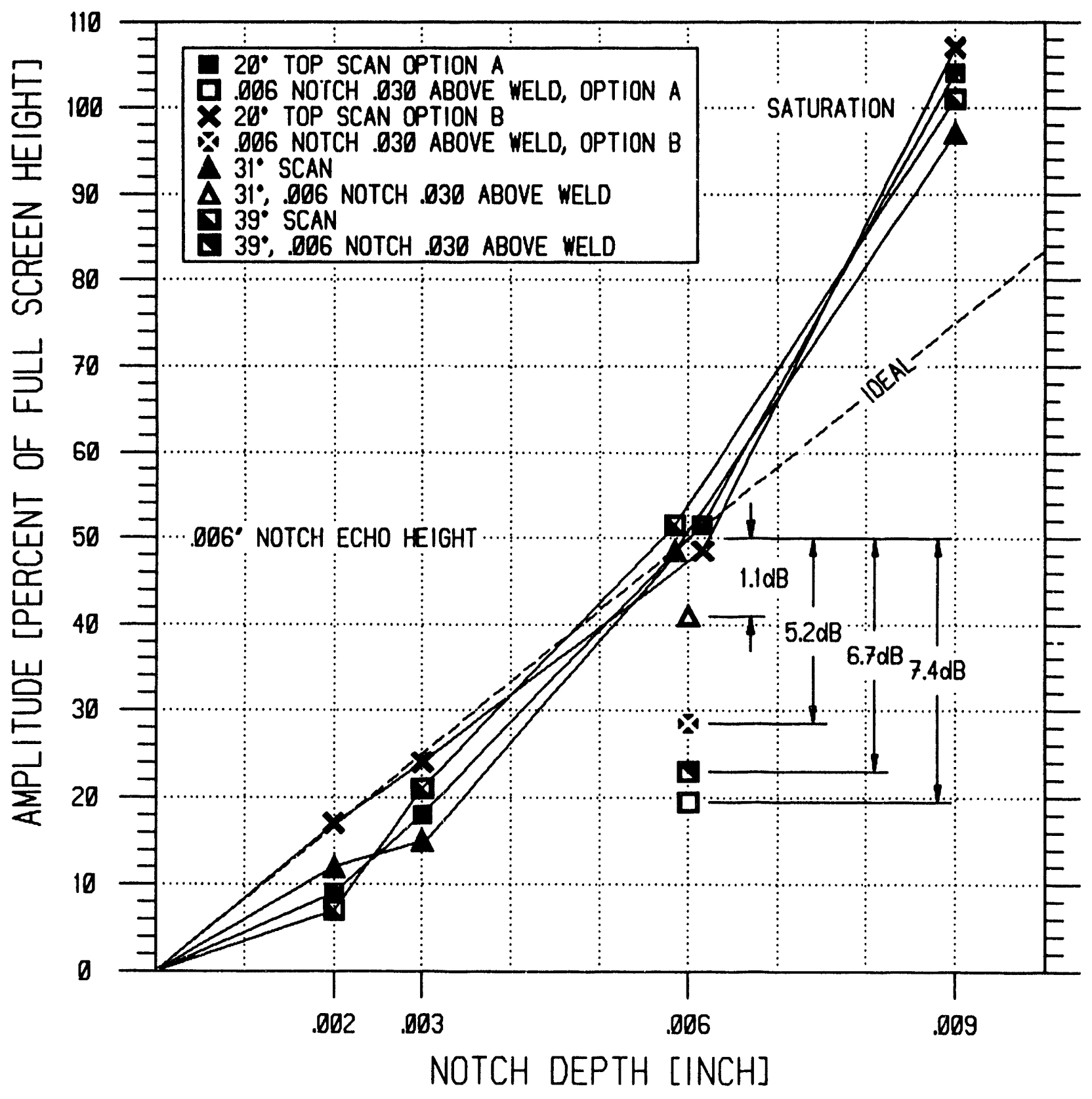

Figure 9. Various Techniques Responses 


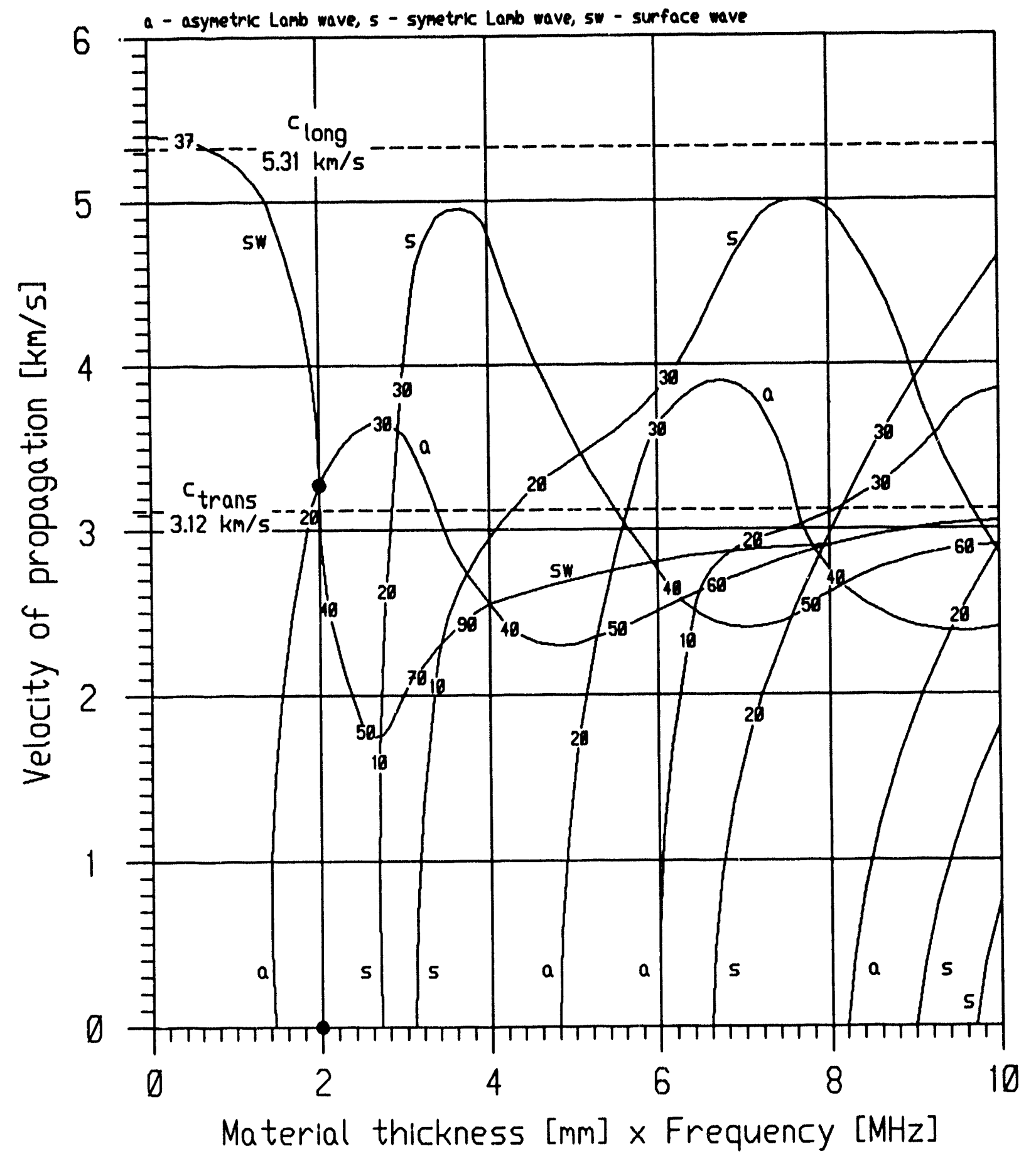

Figure 10. Lamb Wave Mode and Velocity Dlagram 


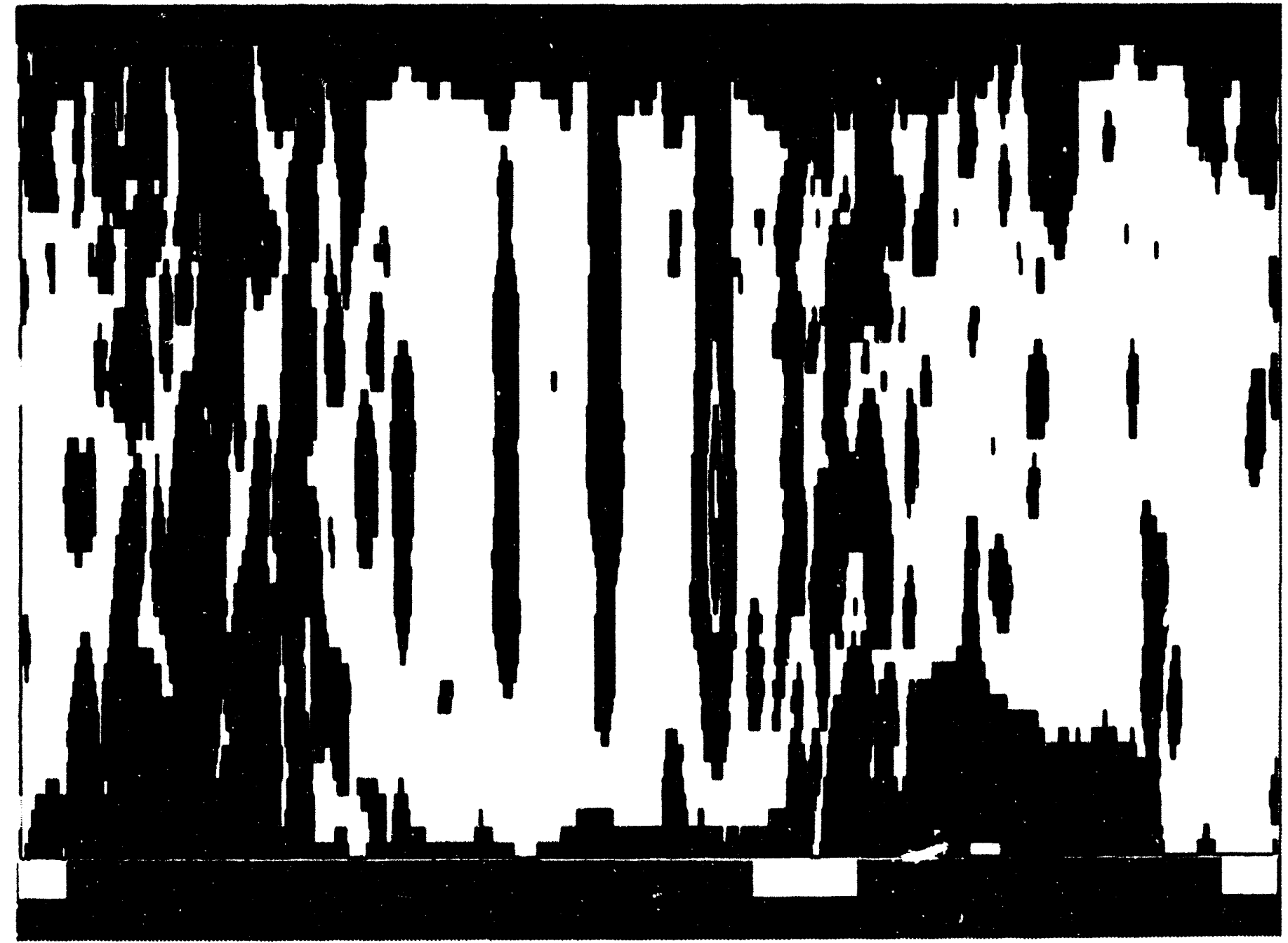

Figure 11. C-scan of Ref. Std. - $31^{\circ}$ Surface Wave 
Arnost Placr

May, 1993
WSRC-TR-93-299

Page 15

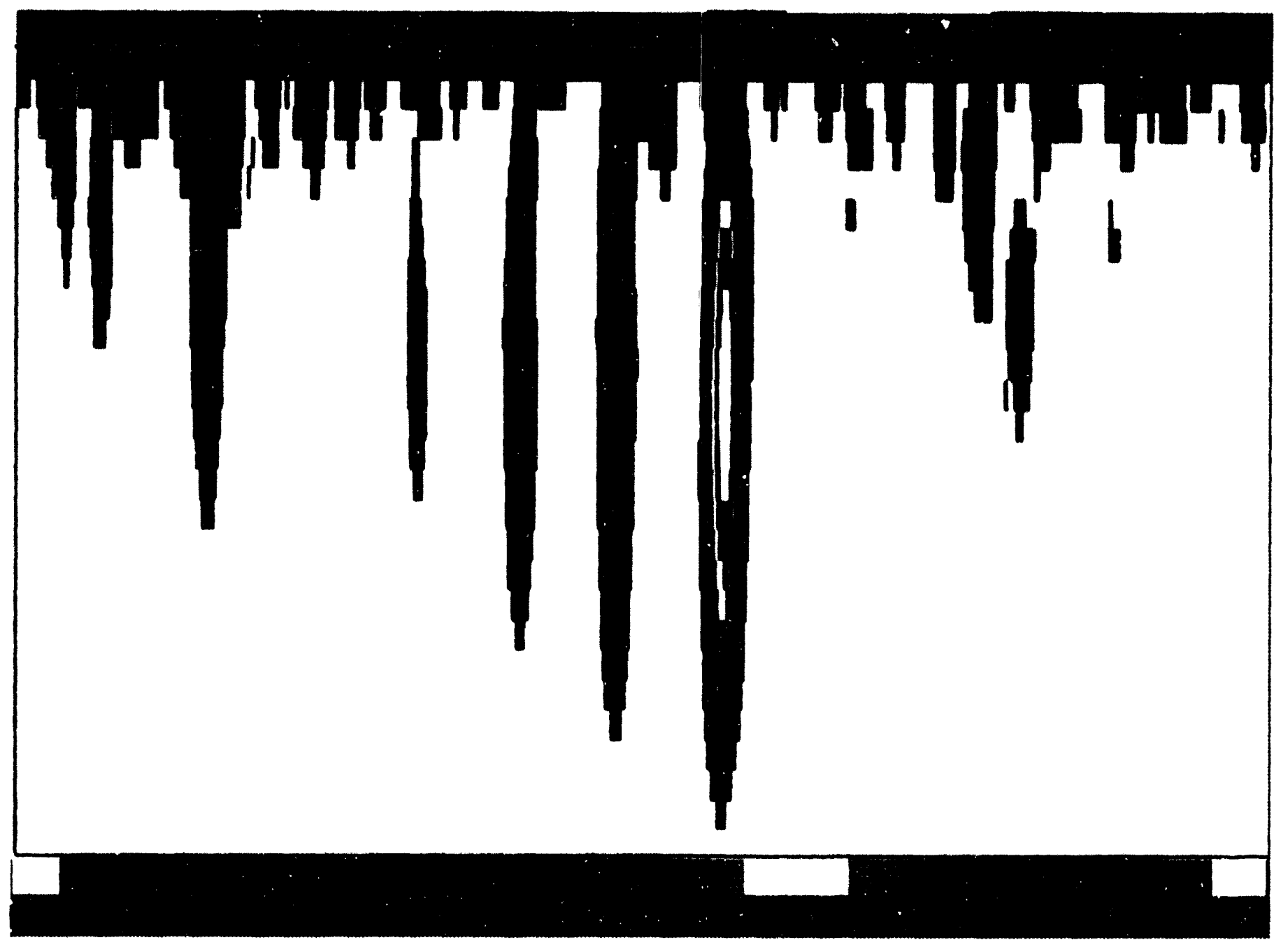

Figure 12. C-scan of Ref. Std. - $39^{\circ}$ Lamb Wave 


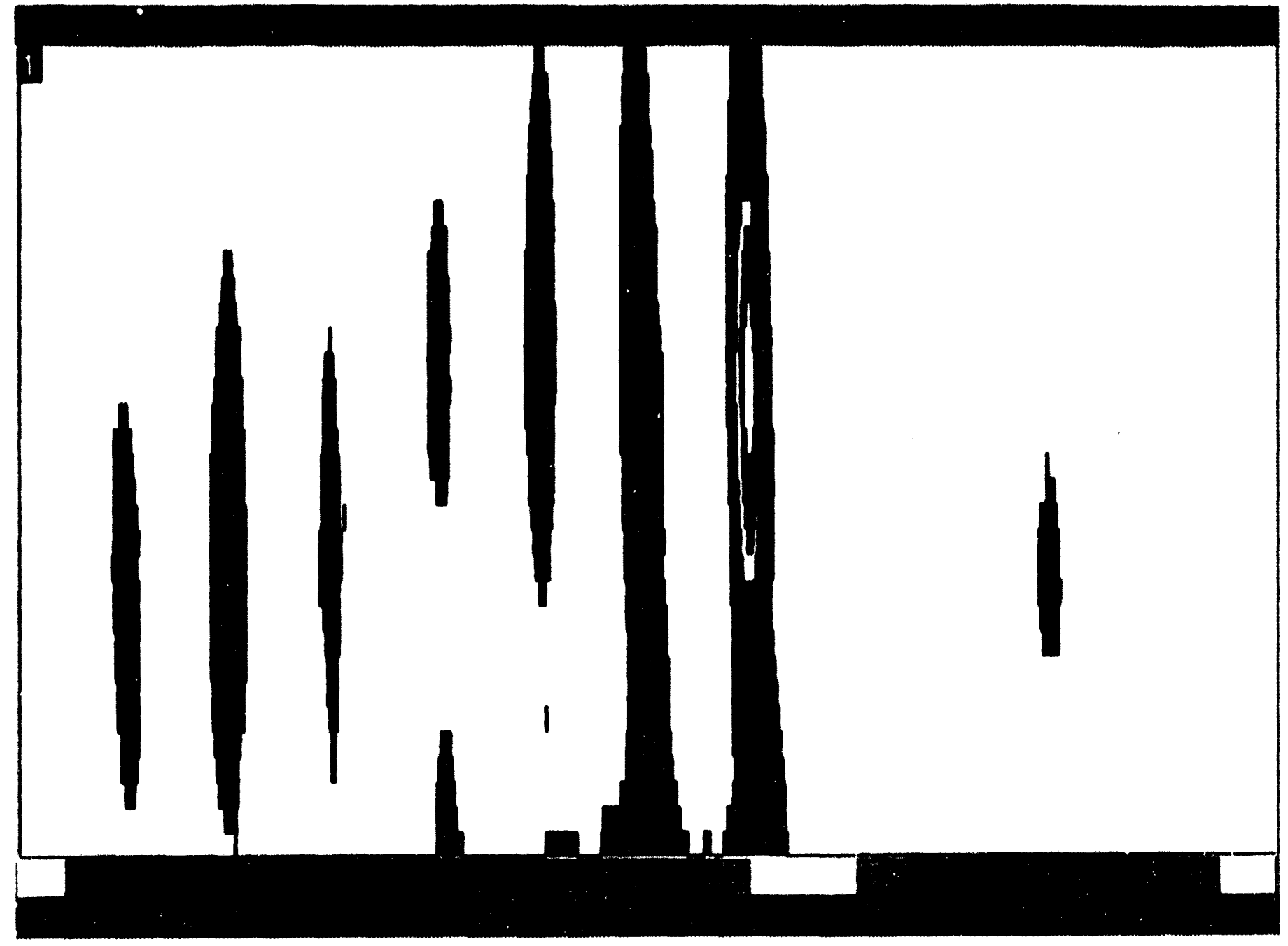

Figure 13. C-scan of Ref. Std. - $20^{\circ}$ Top Scan, Lamb Wave, Option A 


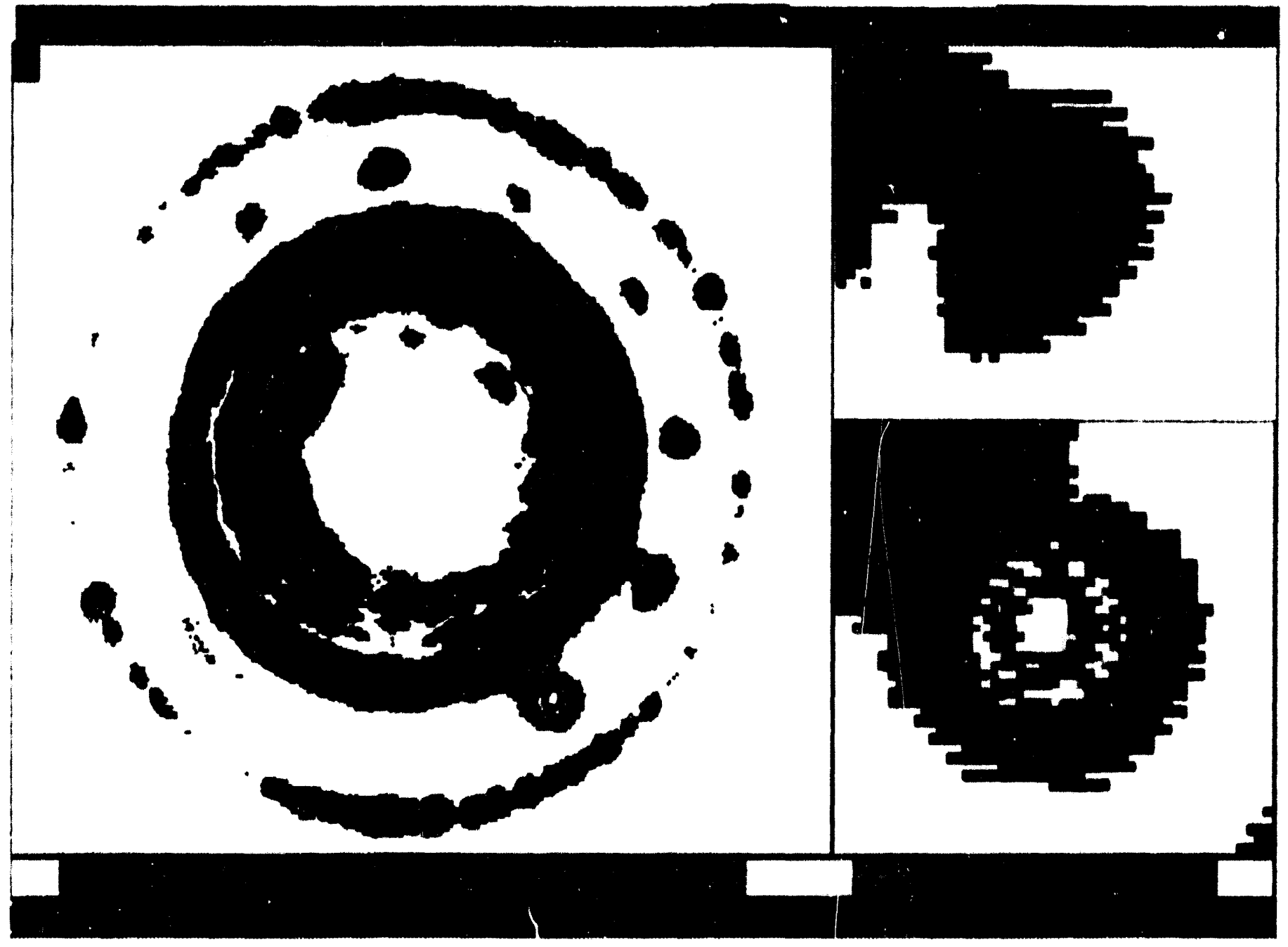

Figure 14. C-scan of Ref. Std. - $20^{\circ}$ Top Scan, Lamb Wave, Option B 
May, 1993

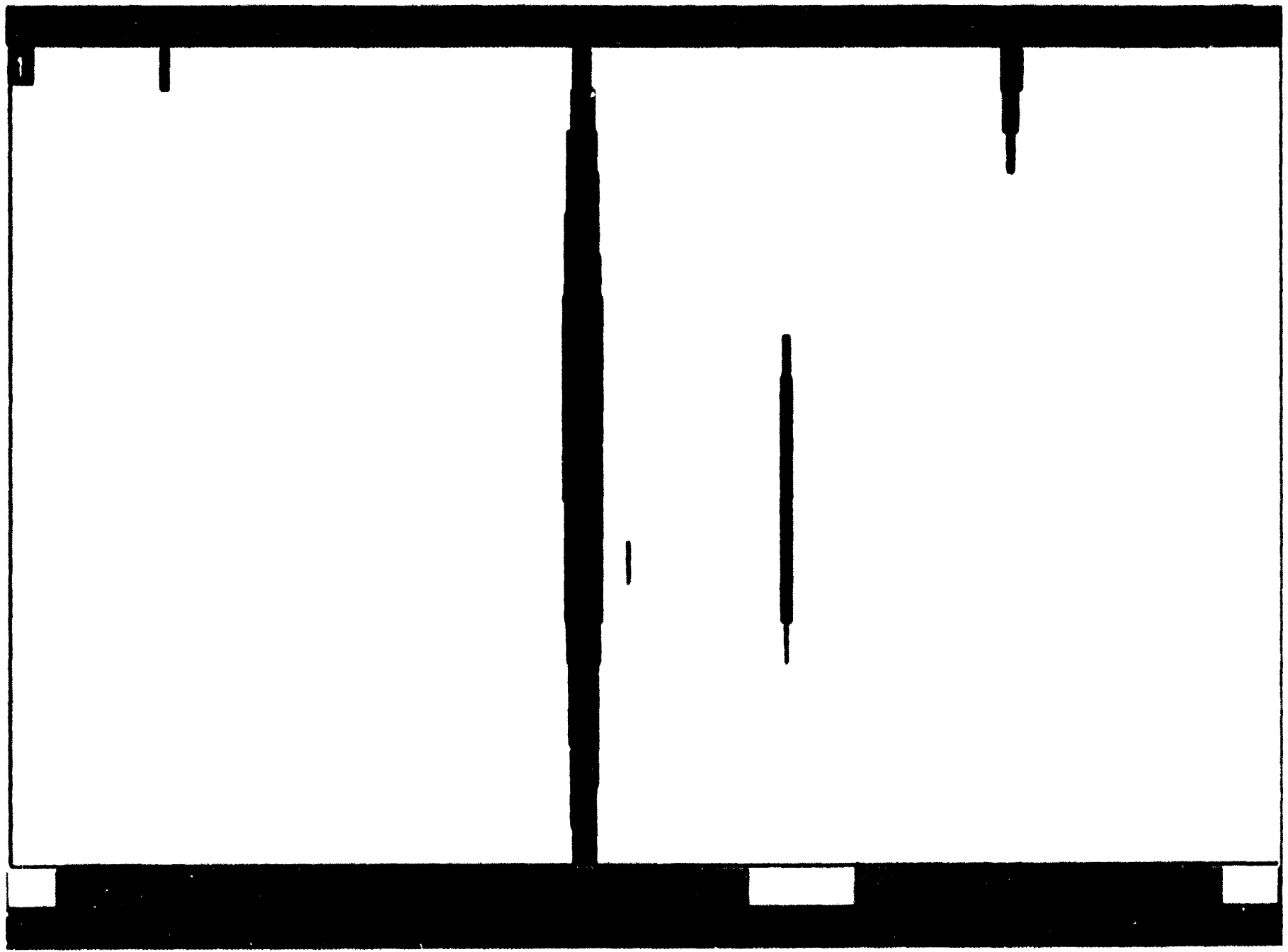

Figure 15. C-scan of part \#36 - $20^{\circ}$ Top Scan, Lamb Wave, Option A 

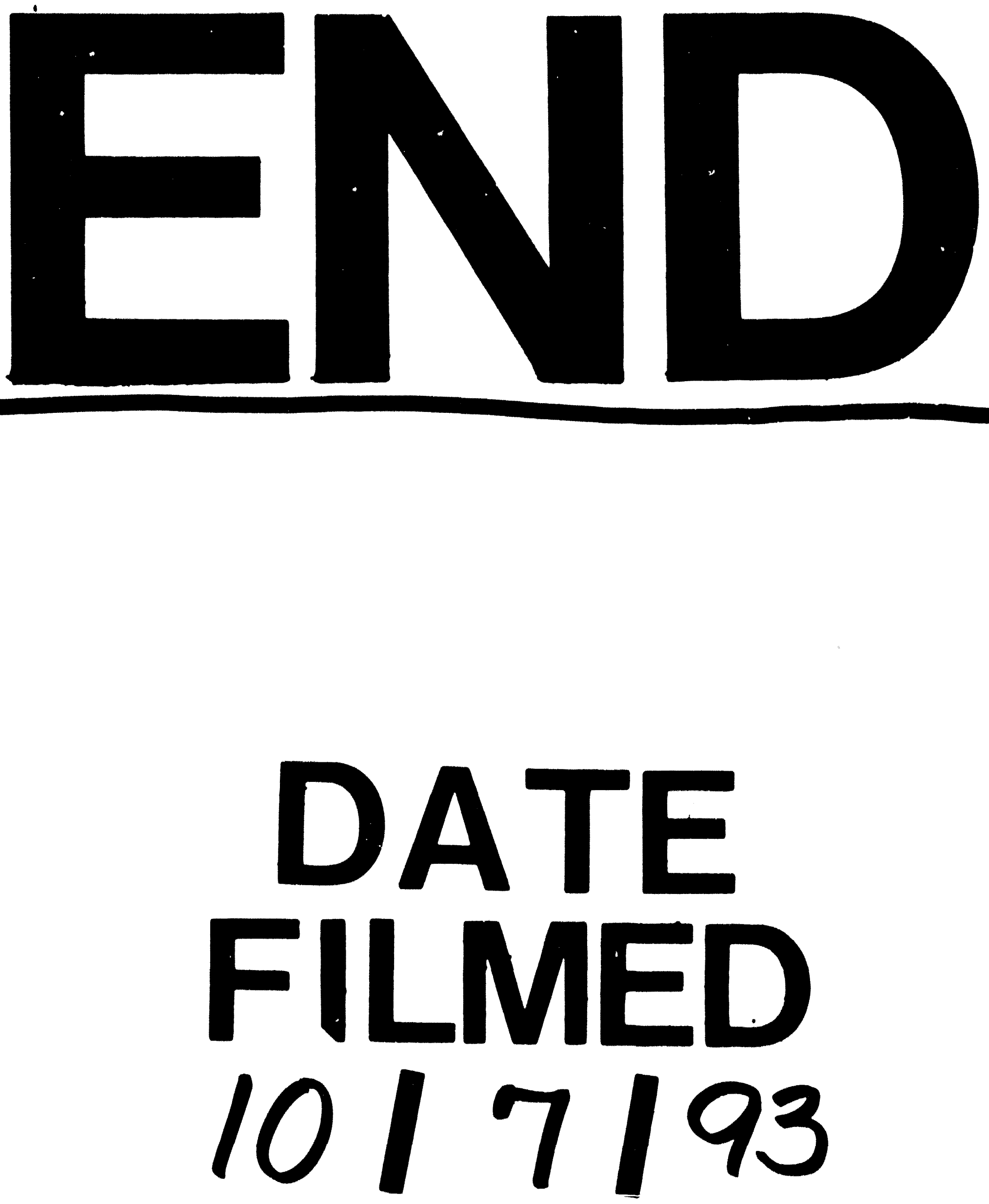
